\title{
The Inspiration of Feng Qi's Thought of Art for Life to Aesthetic Education
}

\author{
$\mathrm{Yu} \mathrm{Zhu}{ }^{1}$ \\ ${ }^{1}$ School of China Jiliang University of Humanities \& Foreign Languages, Hangzhou, Zhejiang 310018, China
${ }^{*}$ Corresponding author. Email: 1042159833@qq.com
}

\begin{abstract}
This paper investigates the theory of "art for life" and the embodiment of aesthetic education in Feng Qi's aesthetic thought, namely, the cultivation of Civilian-style free personality. The contemporary aesthetic education of art cannot be ignored, and its relationship with art is explained through the two layers of life: society and the individual. Art is responsible for the society and reflects the critical reality of the society, but it is also necessary for the freedom of selfthought and the expression of individuality, and the ideal of art should achieve the unity of truth, goodness and beauty.
\end{abstract}

Keywords: Art for life, Aesthetic education, Society, Ideal personality.

\section{INTRODUCTION}

The literary theory of "art for the sake of life" was first proposed in the West in the 19th century, as opposed to the idea of "art for the sake of art". In the 1920s, these two views reached China and led to heated discussions, but what Mr. Feng Qi calls "art for life" is not a one-sided emphasis on the utilitarian nature of art, but more on the role of human beings and the "Civilianstyle free personality"[1] of contemporary Chinese people. This is still relevant to contemporary art education.

The aesthetic concept of "art for art's sake" roughly encompasses ideas such as the non-utilitarian nature of art, the independence of art, and the separation of art from life. The idea of "art for life", on the other hand, highlights the social responsibility that art should assume, emphasizing that the object of art is life and should reflect life. Art is fundamentally created by people, and it cannot be separated from people and society, and in the end it must have a certain influence on society. Therefore, art should be for life, it needs to reflect on society or to promote righteousness, whether in the past when the nation was in danger, or in the present era of peace and prosperity, it is completely necessary to make such advocacy. However, this does not mean that art should be instrumentalized, and the aesthetic role of art should not be neglected, as $\mathrm{Mr}$. $\mathrm{Lu}$ Xun said that art should "open the personality and promote the spirit" and respect the freedom of individual expression [2]; art should also be useful in life and have its aesthetic utility, and the pursuit of the aesthetic value of art works should not be abandoned. . "Art for the sake of life" should be both about life and close to art at the same time.

The idea of "art for life" is the unity between the individual person and the society as a whole. The study of this idea will help to improve the aesthetic ability of our people and will be an important source of inspiration for the cultivation of human personality, freedom of character and development of virtue.

\section{SOCIAL IDEAL TO ART}

The emergence of social ideals is inextricably linked to the background of different times. In modern China, influenced by the West and the national conditions at that time, the concepts of freedom, equality and democracy began to become the core demands of social ideals. From Hong Xiuquan's "The Way of the World is Public"; to Kang Youwei's idea of establishing the "Cosmos" ideal of freedom, equality and fraternity; to Sun Sprouts' "Three People's Principles"; and Li Dazhao Later, Mao Zedong and other communists explored a path from new democracy to socialism and then to communism. All of these ideas are, without exception, "to realize the ideal society through the revolutionary struggle of the masses", which shows that the realization of the social ideal cannot be separated from people and must be based on them. 
Just like Marx's view that the essence of man lies in labor, it is also in labor that the essential power of man is truly realized [3], so that aesthetic ideals and artistic ideals can be associated with social ideals. In his paper, "Marx's Aesthetic Sentiments and Social Ideals," scholar Lu makes the point that "Marx defined the essence of man from the perspective of aesthetics and that aesthetics is the base of his social ideals." [4] The essential power of man lies in free labor, "built according to the laws of beauty", and the most important element of free labor is to obtain aesthetic experience from labor, thus, the "freedom" itself contains the meaning of aesthetics. The connection between beauty and social ideals can be seen in the influence of art on social life.

On the level of the real society, art should have two manifestations in "true". First, art should reflect social life, which is to have certain authenticity; on the other hand, art is not science, but should also provide wisdom and a certain understanding of truth. In addition to these, art should also "reflect the requirements and moral ideals of certain social groups" [5], that is, artistic ideals need to be combined with moral ideals, and such artistic ideals are of positive significance to contemporary social ideals. Just like the aesthetic tradition of "Vajra's Angry Eyes", which began as a description of the appearance of sculptures like Vajra, and later developed into an aesthetic category, as Mr. Feng Qi said, "Art is required to have bones, to be sentimental, and to say that art is for life" [6], which means that art should have social responsibility, and that art works should reveal social contradictions and play a critical role in reality.

But to require all art to conform to the moral requirements and political expression of a particular group's interests is clearly detrimental to the free development of art itself. Feng Qi also considered this point, and he criticized the overemphasis of literature and art to serve politics in China in the 1950s and 1980s, which he considered to be a tendency for literature to become dogmatic [6]. In addition, there was the rise of money-worship in Chinese society from the 1980s onward, which brought harm to the art field. Overemphasizing and advocating the social function of art can harm the independence of art itself, and both tendencies can seriously undermine the freedom and flexibility of artistic creation. It seems that there is a contradiction in the relationship between art and society: art is required to assume certain social responsibilities and embody "advanced morality", but the freedom of artistic creation cannot be undermined as a result. Fundamentally, the crux of the problem lies in the question of which should prevail in artistic creation when the moral expression and political demands of artistic works conflict with the freedom of creation? This is a difficult question, and the key to solving it is what Feng Qi calls the "ideal personality" and the cultivation of the individuality of human aesthetics.

\section{INDIVIDUALIZED AESTHETICS}

What exactly is art? This is a question that is difficult to explain clearly, the most classic of which is Aristotle's discussion in the Poetics, in which he regarded art as an imitation of the real world. Perhaps one should not dwell too much on what is art, but can talk about art with a natural attitude, like the initial image of art was produced by the primitive ancestors for rituals such as dance, music and painting, indicating that art is utilitarian in nature, although later slowly when people are directly confronted with things of beauty they tend not to talk about utilitarianism and enjoy the pleasure brought by beauty, but it can still be found Art is fundamentally utilitarian in nature. In the elaboration of art-related issues, Mr. Feng Che focuses on the practical utility of art, such as "art reveals the logic of life with individualized images and contributes to the freedom and development of human personality [7]."

In China, from the hereditary system instead of the Zen system, ethics gradually become the mainstream of Chinese culture.As Mr. Qian Mu said, "Chinese culture has always been religious and political, political and humanistic, humanistic and artistic", and during these thousands of years, the ethical system has always influenced China, including the influence on art. He always followed the principle of respecting the development of individuality and made a profound criticism of the traditional Chinese philosophy's bondage to human nature, firmly opposing the rational authoritarianism of the three rules and the five rules, and advocating the free development of individuality [8]. Artistic thought is focused on life, and its ultimate purpose is to enable people to come closer to an ideal personality. The artistic ideal comes from the artistic imagination, which is part of the figurative thinking. Artistic imagination requires the infusion of figurative intuition and feelings, the combination of emotions and scenes, which is different from theoretical thinking that uses concepts and categories to grasp reality [9].

What is the influence of art on life, in addition to the utilitarian nature of art as previously mentioned, the relationship between freedom of beauty and individuality should also be focused on. An important principle of a Civilian-style free personality is consciousness and voluntariness, that is, the free will of the person. Like the definition of moral freedom by Feng Qi: a truly free moral act is a conscious and voluntary one, with the unity of the conscious and voluntary principles, the unity of will and reason [10] (P220). And those moral acts that are done through human instincts or habits, which also have good values, are also moral acts, but are not free moral acts. In other words, the utility of art, in its role in society, should be based on the conscious and voluntary free will of the creator in the creation of art in order to meet the requirements of moral claims and political expression. 
Only artistic activities and works created under this premise can truly realize the "art for life", the artistic ideal of freedom of artistic creation and the unity of truth, goodness and beauty.

\section{AESTHETIC EDUCATION AND THE CULTIVATION OF A "CIVILIAN-STYLE FREE PERSONALITY"}

The question of what is the ideal personality has been repeatedly discussed in the history of Chinese philosophy. From the time Confucius proposed the "sage", the "saint" became the most ideal personality in the minds of ancient Chinese people. Professor Gao Ruiquan, in his book Modern Chinese Spiritual Traditions, studied the ideal personality in history and summarized three characteristics of the ideal personality of the "sage": First, the "sage" is absolutely beyond the ordinary people; second, the "sage" has the ability to perfect himself. "The saint has perfection, and the saint has extreme elitism [11]. Therefore, the personality of the "saint" is almost a symbol of a special rational authoritarianism. The most distinctive feature of this personality is that it pursues the "public" of the Divine Principle and ignores or even gives up the "private" of the individual, which is lacking in individuality and difficult for ordinary people to do. Throughout history, there are very few "saints". So in modern times, the ideal personality has changed from "saint" to "commoner", and individual consciousness has gradually awakened.

As to what kind of ideal personality should be cultivated in the present society, we can refer to what Mr. Feng Qi considers as the ideal personality, that is, the "Civilian-style free personality". It is the pursuit of the ideal realm of unity of truth, goodness and beauty. The reason why I say "civilianized" is that this ideal pursuit is different from the pursuit of "saints" in ancient times. The state of reality. This state of reality gradually unfolds in the course of man's continuous pursuit of freedom and his conscious labor. It can be said that the practice of the doctrine of the ideal personality of Archimedes is conducive to the comprehensive development of man [12].

In Feng Qi's view, the formation of human virtue is inseparable from aesthetic education. First of all, using individualized sensual images as a medium can cultivate a person to achieve a truly free personality. For virtue to become a truly free expression of personality and for wisdom to reach rational intuition, it is necessary to realize it through individualized sensual images and aesthetic activities. In addition, the utilitarian nature of art is usually expressed in the positive effect of the aesthetic experience of art and the aesthetic experience on the spiritual uplifting and personality development of man. The value of art lies not only in the spiritual growth of people, but also in the importance of the aesthetic experience for the free and comprehensive development of people. Again, from the perspective of education, the creation of art should be based on the premise of truth and goodness, that is, to cultivate and shape a fully developed and free human being. Aesthetic, moral, and intellectual education are all three important, and each of them should not be neglected [13]. Finally, the practical aspect should be specific to how to cultivate one's aesthetic ability, which in general means exercising one's skills from labor, enhancing rational thinking from learning and thinking, and discovering beauty and improving aesthetic ability from the appreciation of art. In addition to its usefulness to society, art should also have individual and free beauty for individuals. Everyone can enjoy freedom in the appreciation of beautiful things and in the appreciation of artworks, and we can all individually have a beautiful personality. Therefore, the cultivation of this ideal personality can be realized through the way of art, and a "civilianized free personality" is not only a realm of artistic aesthetics, but also a realm of personal life.

\section{CONCLUSIONS}

As an important form of expression of beauty, art cannot be divorced from reality. Whether it is the formalism of "antelope hanging by the horns" or the "vajra rage" in the deep world, art is based on reality and transcends it. In other words, even though art always contains the shadow of reality in tangible or intangible ways, art is not only confined to reality. It can be seen that such "art for life" is not so much about the service of art for life as it is about the mutual satisfaction of life and art.

Art is not only a free and individual expression of our thoughts, but it should also have a social function and be able to undertake certain social responsibilities. The political and moral requirements of "for life" contained in artistic creation and the consciousness and voluntary free will of the creator are equally important, and only works of art created under such a premise can truly realize the freedom of artistic creation and the artistic ideal of unity of truth, goodness and beauty. As $\mathrm{Mr}$. Xu Fuguan said, "Literary and artistic works with real vitality must be conceived from the reality of life, and is actually responsible for the reality of life" [14]. This is called "art for life".

From the standpoint of "art for life," we understand the spirit of art, reflect society, cultivate the ideal personality of individuals, and enhance personal realm. To create a free and open artistic environment is an important guide for artistic creation and the shaping of modern human character, which should also be the vitality of the aesthetic concept of "art for life". 


\section{REFERENCES}

[1] Feng Qi, Human freedom and true goodness and beauty, Shanghai: East China Normal University Press, 2016.pp. 310. (In Chinese)

[2] Chen Guohui, Lu Xun's view of art "for life", Journal of Fine Arts, 2017(04).pp. 93. (In Chinese)

[3] Zheng Huanzhao, On the connotation of Marxism's aesthetic modernity--and the new interpretation of realist aesthetics, Northwest Normal University Journal, 2010(1).pp. 21-22. (In Chinese)

[4] Lu Xiaoguang, Marx's aesthetic sentiment and social ideal, Journal of East China Normal University, 2001(01). pp. 3-4. (In Chinese)

[5] Feng Qi, Human freedom and true goodness and beauty, Shanghai: East China Normal University Press, 2016.pp. 260-261. (In Chinese)

[6] Feng Qi, Human freedom and true goodness and beauty, Shanghai: East China Normal University Press, 2016.pp. 275. (In Chinese)

[7] Feng Qi, Human freedom and true goodness and beauty, Shanghai: East China Normal University Press, 2016.pp. 288. (In Chinese)

[8] Jing Xiaoli, Yang Meng. The inspiration of Feng Che's ideal personality to the moral education of contemporary colleges and universities, Sichuan: Fortune Times. 2021, (02).pp. 208. (In Chinese)

[9] Zhang Lingxin, Feng Qi on beauty and aesthetic ideals, Knowing and doing. 2019, (04).pp. 148. (In Chinese)

[10] Feng Qi, Human freedom and true goodness and beauty, Shanghai: East China Normal University Press, 2016.pp. 220. (In Chinese)

[11] Gao Ruiquan, Modern Chinese spiritual tradition, Shanghai: Shanghai Ancient Books Publishing House, 2005. (In Chinese)

[12] Song Yuhe, An Exploration of Feng Che's Doctrine of Ideal Personality, Wuhan University, 2019. pp. 1. (In Chinese)

[13] Wu Genyou, Wang Bo. A comparison between Feng Qi's "realm theory" and Wang Guowei's "realm theory", Journal of East China Normal University, 2016(03). pp. 133. (In Chinese)

[14] Xu Fuguan, The Complete Works of Xu Fuguan On Intellectual Molecules, Jiuzhou Publishing House, 2014.pp. 113. (In Chinese) 